\title{
Diversity of compounds in femoral secretions of Galápagos iguanas (genera: Amblyrhynchus and Conolophus), and their potential role in sexual communication in lek-mating marine iguanas (Amblyrhynchus cristatus)
}

\author{
Alejandro Ibáñez ${ }^{\text {Corresp., }}{ }^{1}$, Markus Menke ${ }^{2}$, Galo Quezada ${ }^{3}$ ， Gustavo Jiménez-Uzcátegui ${ }^{4}$, Stefan Schulz ${ }^{2}$, \\ Sebastian Steinfartz ${ }^{1}$ \\ ${ }^{1}$ Zoological Institute, Division of Evolutionary Biology, Technische Universität Braunschweig, Braunschweig, Germany \\ 2 Institute of Organic Chemistry, Technische Universität Braunschweig, Braunschweig, Germany \\ 3 Dirección Parque Nacional Galápagos, Puerto Ayora, Santa Cruz, Galápagos, Ecuador \\ 4 Department of Science, Charles Darwin Foundation, Puerto Ayora, Santa Cruz, Galápagos, Ecuador \\ Corresponding Author: Alejandro Ibáñez \\ Email address: alexibanez@mncn.csic.es
}

Background. Chemical signals are widely used in the animal kingdom, enabling communication in various social contexts, including mate selection and the establishment of dominance. Femoral glands, which produce and release waxy secretions into the environment, are organs of central importance in lizard chemical communication. Galápagos marine iguanas (Amblyrhynchus cristatus) is a squamate reptile with lek-mating system. Although the lekking behavior of marine iguanas has been well-studied, their potential for sexual communication via chemical cues has not yet been investigated. Here we describe the diversity of the lipophilic fraction of males' femoral gland secretions among 11 island populations of marine iguanas, and compare it with the composition of its sister species, the Galápagos land iguana (Conolophus subcristatus). We also conducted behavioural observations in marine iguana territorial males in order to explore the possible function of these substances in the context of male dominance in leks. Methods. Femoral secretions were analyzed by Gas Chromatography coupled to Mass Spectrometry (GC-MS), and Gas chromatographwitha flame ionizationdetector (GC-FID) in order to characterize the lipophilic composition. To understand the potential role of femoral secretions in marine iguana intraspecific communication, territorial males were sampled for their femoral glands and monitored to record their head bob rate - a territorial display behaviour in males - as well as the number of females present in their leks. Results. We found that the gland secretions were composed of ten saturated and unsaturated carboxylic acids ranging in chain lengths between $\mathrm{C}_{16}$ and $\mathrm{C}_{24}$, as well as three sterols. Cholesterol was the main compound found. Intriguingly, land iguanas have a higher diversity of lipophilic compounds, with structural group of lipids (i.e. aldehydes) entirely absent in marine 
iguanas; overall the chemical signals of both species were strongly differentiated. Lipid profiles also differed among populations of marine iguanas from different islands, with some islands demonstrating a high diversity of lipophilic compounds (i.e. full spectra of compounds), and others lacking one or more compounds. Among the compounds most frequently found missing were 11- and 13- eicosenoic acids. Gland secretions of males with a better body condition and with a higher dominance status (i.e. those accompanied by females and with higher head bob display) were proportionately richer in $\mathrm{C}_{20}$ unsaturated fatty acids (11-eicosenoid acid). Discussion. Land and marine iguanas strongly diverged in their chemical composition of the femoral glands likely due to ecological differences between both species. Despite that marine iguana populations varied in their femoral gland composition that was not related to their genetic structure. Our results indicated that 11-eicosenoic acid may play an important role in intraspecific chemical communication in marine iguanas. 
1 Diversity of compounds in femoral secretions of Galápagos iguanas (genera:

2 Amblyrhynchus and Conolophus), and their potential role in sexual communication in lek3 mating marine iguanas (Amblyrhynchus cristatus)

5 Alejandro Ibáñez ${ }^{1}$, Markus Menke², Galo Quezada ${ }^{3}$, Gustavo Jiménez-Uzcátegui ${ }^{4}$, Stefan

6 Schulz $^{2}$, Sebastian Steinfartz ${ }^{1}$

$9{ }^{1}$ Technische Universität Braunschweig, Zoological Institute, Division of Evolutionary Biology, 10 Braunschweig, Germany

$12{ }^{2}$ Technische Universität Braunschweig, Institute of Organic Chemistry, Braunschweig, Germany 13

$14{ }^{3}$ Dirección Parque Nacional Galápagos, Puerto Ayora, Santa Cruz, Galápagos, Ecuador 15

${ }^{4}$ Department of Science, Charles Darwin Foundation, Puerto Ayora, Santa Cruz, Galápagos, 17 Ecuador

19 Corresponding Author:

20 Alejandro Ibáñez

21 email: a.ibanez-ricoma@tu-braunschweig.de 
24 Background. Chemical signals are widely used in the animal kingdom, enabling communication

25

26

27

28

29

30

31

32

33

34

35

36

37

38

39

40

41

42

43

44

45

46

47

48

49

50

51

52

53

54

55

56

57

58 in various social contexts, including mate selection and the establishment of dominance. Femoral glands, which produce and release waxy secretions into the environment, are structures of central importance in lizard chemical communication. Galápagos marine iguanas (Amblyrhynchus cristatus) is a squamate reptile with lek-mating system. Although the lekking behavior of marine iguanas has been well-studied, their potential for sexual communication via chemical signals has not yet been investigated. Here we describe the diversity of the lipophilic fraction of males' femoral gland secretions among 11 island populations of marine iguanas, and compare it with the composition of its sister species, the Galápagos land iguana (Conolophus subcristatus). We also conducted behavioural observations in marine iguana territorial males in order to explore the possible function of these substances in the context of male dominance in leks. Methods. Femoral secretions were analyzed by Gas Chromatography coupled to Mass Spectrometry (GCMS), and Gas chromatograph with a flame ionization detector (GC-FID) in order to characterize the lipophilic composition. To understand the potential role of femoral secretions in marine iguana intraspecific communication, territorial males were sampled for their femoral glands and monitored to record their behaviour. Head bob rate - a territorial display behaviour in males - as well as the number of females present in male's leks were recorded. Additionally morphological data of territorial males was collected and correlated with chemical composition. Results. We found that secretions were composed of ten saturated and unsaturated carboxylic acids ranging in chain lengths between $\mathrm{C} 16$ and $\mathrm{C} 24$, as well as three sterols. Cholesterol was the main compound found. Intriguingly, land iguanas have a higher diversity of lipophilic compounds, with structural group of lipids (i.e. aldehydes) entirely absent in marine iguanas; overall the chemical profiles of both species were strongly differentiated. Lipid profiles also differed among populations of marine iguanas from different islands, with some islands demonstrating a high diversity of lipophilic compounds (i.e. full spectra of compounds), and others lacking one or more compounds. 11- And 13- eicosenoic acids were among the most frequently missing compounds. Gland secretions of males with a better body condition and with a higher dominance status (i.e. those accompanied by females and with higher head bob display) were proportionately richer in C20-unsaturated fatty acids (11-eicosenoid acid). Discussion. Land and marine iguanas have differences in their chemical composition of the femoral glands likely due to ecological differences between both species. Despite that marine iguana populations varied in their femoral gland composition that was not related to their genetic structure. Our results indicated that 11-eicosenoic acid may play an important role in intraspecific chemical communication in marine iguanas. 
60

61 Intraspecific chemical communication is a widespread phenomenon among vertebrates (Wyatt 2003). Although reptiles rely heavily on visual signals to communicate with conspecifics, they also use chemical signals in sexual interactions, as well as in a broader social context (Mason \& Parker 2010). Squamate reptiles (lizards and snakes) are very suitable models for researchers aiming to study chemical communication. This is mainly due to highly-developed chemosensory capacity, which is used for intraspecific communication. For instance, substrate-deposited scents are used by snakes to locate partners and/or avoid rivals (LeMaster \& Mason 2003; Shine et al. 2005). Lizards have the ability to produce scent marks that are recognized by conspecifics (e.g. Carazo et al. 2008; Khannoon et al. 2011; Martins et al. 2006). The popularity of lizards as models to study chemical communication has been increasing steadily. However, the functions of the specific compounds that make up chemical signals remain poorly known.

One of the most important organs involved in chemical communication are femoral glands, which are epidermal skin glands situated ventrally on the hind limbs (Mayerl et al. 2015). Reptiles release waxy secretions from their femoral glands that are composed of a mixture of proteins and lipids (Weldon et al. 2008). For example, desert iguanas (Dipsosaurus dorsalis) have heavy femoral secretions, composed of a $20 \%$ lipid fraction and $80 \%$ of protein material (Alberts 1990). Proteins absorb ultraviolet light that could be used by desert iguanas to locate pheromones of low volatility (Alberts 1989). Inter-species variability in proteins from femoral glands suggests that proteins could be used for species discrimination in sympatrically occurring lizard species (Alberts 1991). A recent study on Turks and Caicos iguanas (Cyclura carinata) showed that genetic differentiation among lineages from different islands is reflected by the pattern of proteins in femoral secretions (Welch et al. 2017). In addition, the lipophilic compounds in the femoral secretions play an important role in many types of sexually-mediated behaviour. For example, femoral glands in males of some lizard species emit chemicals that could communicate specific information about the traits of the signaller, and may therefore guide female mate choices (López \& Martín 2005; Martín \& López 2006; Martín \& López 2011; Olsson et al. 2003). A link between chemical signals and dominance has also been suggested. For instance, femoral gland secretions of male Iberolacerta monticola convey information about the individual's dominance status (Moreira et al. 2006). This situation is hardly surprising, given 
90 that the function and activity of femoral glands are regulated by androgens (Fergusson et al. 91 1985). In green iguanas, Iguana iguana, the level of testosterone is positively correlated with the 92 amount of lipids in the femoral secretions of dominant males (Alberts et al. 1992). In this 93 framework, several studies have described the lipid components of the femoral glands in various 94 species of lizards (reviewed in (Martín \& López 2014; Weldon et al. 2008)). Although most 95 96 research on the specific chemicals that compose femoral secretions has focused on lacertids (Heathcote et al. 2014; Martín et al. 2015; García-Roa et al. 2017), a few older studies about iguanids are also available (Alberts 1990; Alberts et al. 1992; Weldon et al. 1990). The femoral secretions of the green iguana I. iguana are known to contain a high diversity of volatile lipids that appear to be received by chemoreception (Alberts 1993; Alberts et al. 1992). These lipids include several saturated and unsaturated fatty acids of different chain lengths $\left(\mathrm{C}_{14-} \mathrm{C}_{26}\right)$, as well as sterols (Alberts et al. 1992; Weldon et al. 1990).

Despite increasing interest in the chemical ecology of lizards, there are no such studies on one of the best known reptile species in the world: the marine iguana (Amblyrhynchus cristatus). This species is endemic to the Galápagos Islands - a world-renowned biodiversity hotspot formed by 13 major islands $\left(>10 \mathrm{~km}^{2}\right), 6$ smaller ones and numerous islets in the eastern Pacific. One of the most interesting aspects of the species' behavioural ecology is its lek-mating system. A lek is defined as a mating system in which there is no parental care, males aggregate in clusters, and females benefit from no resources other than the gametes available in the male territories (Höglund \& Alatalo 1995). Lek-mating behaviour has not been studied in detail for most of reptiles. In contrast, marine iguana lekking has received considerable attention over the past decades, and the system is reasonably well described. At the beginning of the mating season,

112 male iguanas establish small clustered territories along the rocky coastline. These territorial

113 males display head bobbing behaviour in order to attract females to their territories, presumably

114 to mate and also to intimidate competing males that are approaching the territory of the dominant

115 male (Wikelski et al. 1996). However, males that cannot establish territories (marginal males) 116 have far less reproductive success than territorial ones, and basically rely on forced copulations 117 with females that remain outside of the lek territories (Partecke et al. 2002; Wikelski et al. 1996). 118 Apparently, females may benefit from mating within specific males' territories, as the territorial 119 male protects them from harassment by others (Trillmich \& Trillmich 1984; Wikelski et al. 120 1996). The importance of chemical signals in lekking species has been verified in insects. The 
121 mosquito Aedes aegypti uses an aggregation-pheromone to mediate lek establishment (Cabrera \&

122 Jaffe 2007) and males of the sand fly Lutzomyia longipalpis may use pheromones to attract

123 females to their leks (Jones \& Hamilton 1998). Therefore, the lek-mating system offers a

124 valuable natural setup to investigate questions regarding chemical signalling.

125 Several factors suggest that marine iguanas might rely heavily on pheromones for 126 intraspecific communication. Firstly, they possess femoral glands thatare the source of chemical

127 signals for many species of lizards (Mayerl et al. 2015). Secondly, observations have revealed a 128 "substrate-licking" behaviour in marine iguanas; (Carpenter 1966) observed that male iguanas 129 protrude their tongue onto the lava rocks as if testing for scent marks. Further, female iguanas 130 have been reported to lick the sand intensively when exploring new areas to lay eggs (Rauch 131 1988). Tongue licking is a chemoreceptive response to recognition of marked substrates in 132 iguanids (De Fazio et al. 1977; Krekorian 1989) and suggests that A. cristatus might use 133 conspecific olfactory cues for intraspecific communication.

134 Our study is the first to analyze the lipophilic fraction of femoral gland secretions in 135 Galápagos iguanas. By performing intensive sampling of all major island populations and 136 subspecies of marine iguanas (see (Miralles et al. 2017)), we seek to characterize the lipophilic 137 profile of femoral glands, as well as to explore the variation between populations originating 138 from distinct islands of the archipelago. In addition to sampling marine iguanas, we also 139 collected femoral secretions of land iguanas (Conolophus subcristatus). Conolophus is the sister 140 lineage of Amblyrhynchus, having diverged around 4.52 million years ago, most likely on the 141 Galápagos Archipelago (MacLeod et al. 2015). Therefore, we compare the chemical profile of 142 marine iguanas with their closest taxon, to investigate the level of differentiation in chemical 143 signals between the two. Marine iguanas have a great mobility and could even be passively 144 dispersed by oceanic currents (Carpenter 1966; Higgins 1978; Lanterbecq et al. 2010). 145 Therefore, we expect that chemical composition has a low variation among populations of 146 marine iguanas. In contrast, we hypothesize that land and marine iguanas diverge strongly in 147 their chemical signals because they occupy totally distinct habitats and there is no gene flow 148 among both species.

149 A further aim of this study was to understand the functions of femoral gland compounds 150 in marine iguanas. For this purpose, we carried out behavioural observations in one population of 151 A. cristatus. Morphological and behavioural data of territorial males were collected during the 
152 breeding season and correlated with data on gland chemistry. Body size, as well as the body 153 condition index, of male marine iguanas were estimated as determinant factors for female mate 154 choice and male dominance hierarchy (Wikelski et al. 1996). Territorial males were regularly 155 monitored to estimate their head-bobbing rate, and the presence of females in their territories was 156 recorded. Head-bobbing is a behaviour typically displayed by territorial males to defend their 157 territories from other males, as well as to attract females during the breeding season (Wikelski et 158 al. 1996). Dominant males, i.e. those with high display levels (i.e. frequent head bobbing) and 159 who are accompanied by females, should release certain chemicals in their territories that inform conspecifics of their status.

METHODS AND MATERIALS

163

\section{Femoral gland sampling}

During the months of December and January of the years 2014 - 2016 (a period coinciding with the mating season of marine iguanas), an overall of 196 iguanas were captured in 11 islands of the Galápagos archipelago in order to sample their femoral glands. Of those, a subsample of 134, representing all major island populations and subspecies (see Table S1 and Fig. 1 for an overview), were used to examine the variation of chemical profiles among populations. However, due to uneven sampling effort, the number of obtained samples per population was unequal. Therefore a subset of 103 samples, with even sample size for each population was randomly selected and used in statistical analyses in order to avoid any effects of an unbalanced design. The remaining samples (62) were taken from territorial males of a single population (i.e. A. cristatus mertensi from La Lobería on San Cristóbal) and used to understand the function of chemical signals in intraspecific communication. In this way, chemical composition of femoral secretions could be analyzed in relation to individual morphology and behaviour (see below: Morphological dataset and Behavioural dataset). The marine iguanas were captured using a pole with a lasso, and their femoral secretions were obtained by gently squeezing the femoral glands. Femoral secretions were then placed in a $2 \mathrm{ml}$ glass vial with dichloromethane. All samples were stored cold (in portable coolers at approximately $4-8{ }^{\circ} \mathrm{C}$ ) during the field work, 
182 and subsequently transported to laboratories in Germany where they were stored at $-80{ }^{\circ} \mathrm{C}$, until 183 chemical analysis were performed.

184 In addition, during January 2016, we also sampled the femoral glands of three individuals 185 of land iguana C. subcristatus, which are housed in a spacious outdoor enclosure at the Charles 186 Darwin Research Station on Santa Cruz Island.

187 The Galápagos National Park authority granted the research permission for this study 188 (permit numbers: PC-22-14, PC-08-15 and PC-09-16).

189

\section{Chemical analysis and lipid characterization}

191

192 The chemical analyses were performed by Gas Chromatography coupled with Mass 193 Spectrometry (GC-MS), and Gas chromatograph with a flame ionization detector (GC-FID). GC194 MS analyses of natural compounds were performed on a GC 7890A/MSD 5975C from Agilent. 195 Mass spectrometry was performed in an electron ionization mode (EI) with 70 eV. Fused-silica 196 capillary columns and HP-5MS (Agilent Technologies, $30 \mathrm{~m}, 0.25 \mathrm{~mm}$ i.D. $0.25 \mu \mathrm{m}$ film 197 thickness) were used, with helium as the carrier gas. GC-FID was performed using a HP-5 198 column (Agilent Technologies, $30 \mathrm{~m}, 0.25 \mathrm{~mm}$ i.D. $0.25 \mu \mathrm{m}$ film thickness) using hydrogen $\left(\mathrm{H}_{2}\right)$ as the carrier gas with a flame ionization detection (FID) system.

The temperature program for the GC-MS was: 50-5-5-320 $\left(50{ }^{\circ} \mathrm{C}\right.$ starting temp., hold time $5 \mathrm{~min}$ then $5^{\circ} \mathrm{C} / \mathrm{min}$ increase up to $320^{\circ} \mathrm{C}$ ). For GC-FID with autosampler the temperature program $125-5-5-320\left(125^{\circ} \mathrm{C}\right.$ starting temp., hold time $5 \mathrm{~min}$, the $5{ }^{\circ} \mathrm{C} / \mathrm{min}$ increase up to $320^{\circ} \mathrm{C}$ ) was used.

The samples collected in December 2014 and January 2015 were preserved in $500 \mu \mathrm{L}$ dichloromethane. Aliquots of $20 \mu \mathrm{L}$ from each sample were taken for derivatizations, and $0.8 \mu \mathrm{L}$ of internal standard (tridecyl acetate) was added. The samples collected in December 2015 and January 2016 were stored in $200 \mu \mathrm{L}$ dichloromethane. Aliquots of $5 \mu \mathrm{L}$ were taken for derivatizations and $0.4 \mu \mathrm{L}$ of internal standard (tridecyl acetate) was added, adding extra $20 \mu \mathrm{L}$ dichloromethane. The addition of the internal standard ensured that similar concentrations of the samples were injected into the GC/MS system. 
213 into their corresponding methyl ester (Black 1983). Elucidation of the structure was performed

214 by mass spectral comparison with data bases, and comparison with reference compounds

215 identified 13 major compounds. Fatty acids were identified as their corresponding methyl esters

216 (Table 1). In contrast to marine iguanas, land iguana samples also feature aldehydes in addition

217 to carboxylic acids (Table 1). Besides the additional aldehydes, hexadecyl hexadecanoate and di-

218 (9-octadecenoyl)-glycerol were also found (Table 1). The position of the double bonds was

219 confirmed by dimethyl disulfide (DMDS)/ $\mathrm{I}_{2}$-derivatization of methylated natural samples

220 according to published procedures (Bruns et al. 2013; Buser et al. 1983).

221

\section{Morphological dataset}

223

224 Morphological data and femoral secretions were collected in a group of territorial males to 225 explore whether the chemical compounds might inform of certain morphological traits relevant 226 for mate choice and/or dominance status. For this part, we focused on a single population (i.e. $A$. 227 cristatus mertensi from La Lobería, San Cristóbal Island).

228 During December 2014 and January 2015, a total of 53 male marine iguanas were 229 measured for their snout-ventral length (SVL) using a metric-tape $( \pm 1 \mathrm{~mm})$, and for head width 230 (distance across the jaw at the widest point) using a calliper $( \pm 0.1 \mathrm{~mm})$. Body mass was 231 recorded using a portable field scale $( \pm 10 \mathrm{~g})$. In addition, femoral gland secretions were also 232 taken from all captured iguanas.

233 We estimated the relative head size as the residuals of a linear regression of log234 transformed head size versus SVL. The body condition was calculated as the residual from a 235 linear regression between body mass and SVL (both log-transformed) (Krebs \& Singleton 1993;

236 Wikelski \& Romero 2003).

237

238 Behavioural dataset

239

240 In order to understand the role of chemical signals in marine iguana lek-systems, we performed 241 an observational study at the La Lobería colony in San Cristóbal during the period from 242 14/12/2015 until 06/01/2016. 
243

244

245

246

247

248

249

250

251

252

253

254

255

256

257

258

259

260

261

262

263

264

265

266

267

268

269

270

271

272

273

The study consisted of two parts performed in parallel: 1) a count to estimate the number of iguanas in the study area was conducted;2) the behaviour of territorial males in selected leks was recorded and their femoral glands were sampled.

\section{Marine iguana count}

A daily count was performed to provide a rough overview of the number of marine iguanas in our study site (in total 12 days). In each count, the observer walked along the coastline, counting all iguanas visible within the range of a $\sim 1.5 \mathrm{~km}$ transect. The marine iguanas were classified in three categories on the basis of their external features: territorial males, female-sized individuals and juveniles, following the classification characteristics of MacLeod (et al. 2016). Territorial males have enlarged dorsal crests, large body size and conspicuous breeding coloration. Femalesized individuals lack such features, with their mostly dark and uniform coloration that contrasts with the colourful red and green patches of the males. However, female-mimicking males or sneakers cannot be identified by external features (Wikelski et al. 1996) and therefore we were not able to distinguish sneaker males from females and both were classified as "female-sized" individuals. Juveniles can be easily distinguished by their smaller size (approximately less than $70 \mathrm{~cm}$ in total length). Average numbers and standard deviations (SD) are given for each category in the results section. The marine iguana count performed in this study intended to provide a general idea of the number of iguanas in our study area but population size for $A$. cristatus in this island has been already estimated from a mark-recapture study (see (MacLeod et al. 2016)).

\section{Monitoring of territorial males}

The behaviour of 9 territorial males was monitored in their lek-mating areas. For this, we selected two different sites at the "La Lobería" breeding colony on San Cristóbal (subspecies $A$. c. mertensi) and an additional site on the neighbouring island of Santa Cruz (A. c. hassi). Territorial males from each site were photographed at the beginning to allow identification from digital images, and marked with numbers on the flanks using non-permanent white paint to allow individual recognition during the observations. Territorial males show strong site-fidelity and 
274 occupy the same territorial areas during the entire reproductive season (Wikelski et al. 1996). We 275 made an overall of 55 observations on focal territorial males, each lasting between 15 and 60 276 minutes, during which we noted the number of head bobs in each observation period.

277 Observations were made between 8 am and $6 \mathrm{pm}$ local time always on sunny days. The head 278 bobbing rate was then calculated by dividing the total number of head bobs recorded by the total 279 time of the observation in minutes. We also monitored the presence or absence of females in the 280 male territory (females were considered as 'present' when one or more females were within 281 approximately two body lengths of the focal male).

282

\section{Statistical analysis}

284

285 The proportions of the compounds were re-standardized by calculating the relative contribution 286 of each compound (peak area of a focal compound) with respect to the total peak area for all substances. Statistical analyses were performed with the interface Rstudio in R software version 3.3.2 (R Development Core Team 2013), as well as with Statistica v8.0 (Statsoft Inc., Tulsa, OK, USA).

A permutational multivariate ANOVA (PERMANOVA) was used to test for significant differences in chemical profiles among the different islands. Multiple pairwise comparisons were performed by correcting for multiple testing on the basis of the Benjamini-Hochberg (B-H) method, which controls for false-discovery rate (Benjamini \& Hochberg 1995). Additionally, we plotted the data in two dimensions using Non-Metric Multidimensional Scaling (NMDS). We used SIMPER (similarity percentage analysis) to assess which compounds contributed most to differences among populations (package "vegan"; Oksanen et al. 2011). This analysis allows identifying which compounds contribute more to the observed pattern of similarity.

Furthermore, the relationship between morphological and behavioural variables, and the proportion of specific lipids was examined in marine iguanas. In order to explore the degree of collinearity in chemical composition data, a Principal Component Analysis (PCA) was performed on the 13 lipophilic compounds, including those from the individuals for which morphological or behavioural data had been gathered. We used the PCA to reduce the

303 dimensionality of the data, and to detect co-linearity among the levels of the various compounds.

304 Therefore, to avoid including co-linearity among independent variables in subsequent model 
305 development, only those compounds that correlated best with each PC factor (i.e. variables with

306 the highest loadings) were used, and the remaining compounds were discarded (following

307 (Dormann et al. 2013); see Table S2). Compounds that correlated strongly with each PC factor

308 were selected as independent variables for further modelling, these were: tetracosanoic acid,

309 hexadecanoic acid, 11-eicosenoic acid and 9-octadecenoic acid.

310 In order to test the relationship between morphology and proportion of the volatile

311 compounds in secretions, we built three linear models which considered body size (SVL), body

312 condition, and relative head size as dependent variables, with the proportion of selected

313 compounds as explanatory variables. The probability that the chemical profile of a given male

314 influenced whether or not he was accompanied by females was modelled using a mixed effects

315 logistic regression (binomial family, "glmer" function of package: "Ime4"; (Bates et al. 2014)).

316 The identity of the male was considered as a random factor. The best model, including the best

317 subset of independent variables, was selected following the AIC corrected for small sample size

318 with the use of the "glmulti" package (Calcagno 2013). As some iguanas had no 11-eicosenoic

319 acid, we tested whether the presence of this chemical explained their head bobbing behaviour by

320 performing a non-parametric Mann-Whitney U-test.

321

322 RESULTS

323

324 Diversity of lipids in femoral glands of Galápagos iguanas

325

326 A total of 13 lipids from marine iguanas were identified and quantified (Table 1 and Fig. 2). We

327 characterized 10 carboxylic acids with chain lengths ranging between $\mathrm{C}_{16}$ and $\mathrm{C}_{24}$, as well as 328 three steroids. The most common compound in the femoral glands was cholesterol (31.14\%) 329 followed by hexadecanoic acid (22\%). $\mathrm{C}_{20}$-unsaturated fatty acids, such as 11-eicosenoic acid $330(0.35 \%)$ and 13 -eicosenoic acid $(0.1 \%)$, were the rarest compounds in marine iguana secretions.

331 A total of 20 volatile compounds were found in the femoral glands of land iguanas. Of

332 these compounds, 8 were found in C. subcristatus but not in A. cristatus (Table 1). The exclusive

333 compounds included saturated and unsaturated carboxylic acids, as well as aldehydes.

334 Interestingly, aldehydes were totally absent in marine iguana femoral glands, and thus were 
335 specific to land iguanas. 13-Eicosenoic acid was absent in land iguanas, but present in some 336 populations of marine iguanas (Table 1,2).

337 Lipophilic profiles varied greatly among island populations of marine iguanas (Table 2,

338 Fig. 3). All populations shared 8 compounds, these were: Hexadecanoic acid, 9-octadecenoic 339 acid, octadecanoic acid, 5, 8, 11, 14-eicosatetraenoic acid, eicosanoic acid, docosanoic acid, 340 tetracosanoic acid and cholesterol. Marine iguanas from some islands (e.g. Isabela, Santa Cruz, 341 San Cristóbal (La Lobería), Floreana and Santiago) had the full range of lipids, thus presenting a 342 high chemical diversity. However, other islands lacked one or more compounds (e.g. Española, 343 Marchena, Pinta, and Genovesa). This case was especially striking in Pinta and Genovesa, in 344 which the diversity of lipids was the lowest of the entire archipelago, with only 8 and 9 lipophilic 345 compounds, respectively. $\mathrm{C}_{20}$-unsaturated fatty acids (i.e. 11- and 13-eicosenoic acids) were 346 most often absent in marine iguana populations (Table 2). Accordingly, the chemical 347 composition was dependent on population origin (PERMANOVA, Pseudo $\mathrm{F}_{11,91}=7.57, P=$ 348 0.001, Fig 3). Pairwise comparisons revealed significant differences among lipids of some 349 populations (Table S3). Surprisingly, secretion chemistry differed between populations 350 inhabiting different islands, but belonging to the same genetic cluster (e.g. Fernandina-Isabela 351 and Española-Floreana, see Table S3 and Table S4). Conversely, some populations belonging to 352 different genetic clusters had similar chemical profiles (e.g. Pinta-Santa Fe and San Cristóbal353 Fernandina). In the case of the iguanas from Punta Pitt and La Lobería, which inhabit the same 354 island (San Cristóbal) but are genetically distinct, pairwise comparisons showed that their 355 chemical secretions are rather similar (corrected $P=0.21$ ).

\section{Morphological and behavioural data}

The body size (SVL) of focal marine iguanas ranged from $35 \mathrm{~cm}$ to $54 \mathrm{~cm}$, and body mass ranged from $3 \mathrm{~kg}$ to $7.75 \mathrm{~kg}$. The body condition index ranged from -0.40 (worst condition) to 0.26 (best condition). Male iguanas had a minimum head width of $3.6 \mathrm{~cm}$ and a maximum of 7.8 362 $\mathrm{cm}$.

The average number of marine iguanas observed in the study area per study day was 135 .

364 Female-sized were the most abundant group (average $\pm \mathrm{SD}=78 \pm 8$ ), followed by territorial 365 males $(57 \pm 8)$ and juveniles $(10 \pm 4)$. The head bobbing rate of the focal males ranged from 0.73 
366 to 2.40 head bobs per minute. Some males were never accompanied by females, while others had

367 females in their territories during all the observations (raw behavioural data is shown in Table 368 S5).

369

370

\section{Functional correlates of femoral secretions with behaviour}

371

372

The PCA summarizes the variation of the 13 chemical compounds in four PCs, accounting for a

373 total of $75 \%$ of the variation. The first PC (eigenvalue $=3.96$, variance $=30.4 \%$ ) correlated best with tetracosanoic acid (coefficient loading $=0.89)$. The second PC $(2.39,17.23 \%)$ correlated most with hexadecanoic acid (0.89). The third PC $(1.98,15.21 \%)$ showed the highest correlation with 11-eicosenoic acid (0.89). Finally, the fourth PC (1.6, $12.3 \%$ ) correlated with 9octadecenoic acid (0.78).

The best explanatory model for male body condition included two variables: 11eicosenoic acid and tetracosanoic acid (adjusted $\mathrm{R}^{2}=0.24, \mathrm{~F}_{2,46}=8.41, \mathrm{P}<0.001 ; 11$-eicosenoic acid: estimate $=16.18, \mathrm{t}=3.64, \mathrm{P}<0.001$; tetracosanoic acid: estimate $=5.31, \mathrm{t}=2.32, \mathrm{P}=0.02$;

381

382

383

384

385

386

387

388

389

390

391

392

\section{DISCUSSION} $7, \mathrm{P}=0.05$, Fig. 6).

Fig. 4). Body size (SVL) and relative head size were both independent of the proportions of the chemicals found in the femoral glands (all $\mathrm{P}>0.10$ ).

The best model (i.e. lowest AICc, see Table 3) that predicted the probability of having females in a male's territory included only one of the chemical compounds, i.e. 11-eicosenoic acid. Males with higher proportions of 11-ecoisenoic acid were more likely to be accompanied by females (estimate $\pm \mathrm{SE}=496.6 \pm 166.5, \mathrm{Z}=2.98, \mathrm{P}=0.003 ;$ Fig. 5).

Furthermore, presence of 11-eicosenoic acid in femoral glands also correlated with an increased head bobbing rate. Territorial males with 11-eicosenoic acid showed more head bobs per minute (median $=1.84)$ than those lacking that compound $($ median $=1)($ See Table S4). However, this difference was only marginally significant (Mann Whitney $U$ test: $Z=-1.94, N=$

394 
395 Although many researchers have focused their attention on the ecology, behaviour and 396 microevolution of the Galápagos iguanas, studies on the chemical communication in these iconic 397 reptiles have so far been neglected. Our study is the first to survey the lipophilic compounds of 398 Galápagos iguanas, and to explore their possible function for intraspecific communication in $A$. 399 cristatus. Unlike many studies focusing on the chemistry of femoral gland secretions in lizards 400 (reviewed in (Weldon et al. 2008)), we surveyed not one but all major island populations of 401 marine iguanas, providing a complete overview of the intraspecific variation of lipophilic 402 substances in this species. In the following section, we discuss the general patterns of lipophilic 403 diversity between land and marine iguanas, as well across marine iguana populations. 404 Furthermore, we describe the composition of specific lipid compounds and their possible 405 functional correlates for chemical communication in the context of lek-mating.

406

407 Diversity of femoral lipids in Galápagos iguanas

408

409 The lipid profiles of marine and land iguanas were different. A total of 13 and 20 different lipids 410 were found in marine iguanas and land iguanas, respectively (Table 1). In detail, eight 411 compounds (fatty acids and aldehydes) were found in land iguanas but not in marine iguanas.

412 Most surprisingly, many of these compounds are aldehydes, a group of lipids that is completely 413 absent in marine iguanas, making these substances a characteristic difference between land and 414 marine iguanas. It is likely that land iguanas might have one or more enzymes that catalyze the 415 production of aldehydes. Given that land and marine iguanas diverged around 4.5 million years 416 ago on the Galápagos archipelago (MacLeod et al. 2015), enzymes catalyzing aldehyde synthesis 417 might have evolved independently in the land iguana lineage. Alternatively, genes for these 418 enzymes might have been lost in the marine iguana lineage, or are now down-regulated. A 419 transcriptome/genome analysis of both land and marine iguanas, as well as of closely related out420 group taxa, such as members of the genus Ctenosaura from Central America, could shed light on 421 these alternative explanations. Interestingly, aldehydes are present in the lizard Psammodromus 422 algirus (Martín \& López 2006), but not in a phylogenetically close species, P. hispanicus (López 423 \& Martín 2009). The presence of aldehydes in P. algirus could have a functional environmental 424 constraint, as this species inhabits grassy areas where substrate scent marking is difficult, and 425 therefore the presence of highly volatile substances like aldehydes would be more suitable for 
426 short-range communication (Martín \& López 2014). In the case of Galápagos iguanas,ecological 427 factors might also be possible drivers for the observed divergence in chemical signals between 428 both species. For example, in marine iguanas, marking rocky substrates could be essential for 429 establishing territories by dominant males. For this purpose, aldehydes may be poorly suited 430 since they volatilize too rapidly in the high humidity conditions, while carboxylic acids and 431 steroids would persist longer. A recent study on chemical signal functionality of terrestrial 432 vertebrates (amniotes) found that aldehydes are emitted from the sender's body rather than from 433 scent marks, likely due to their susceptibility to oxidation and degradation that would limit their 434 persistence in scent marks (Apps et al. 2015). Interestingly, aldehydes occurring in body odours 435 are much shorter than those found in land iguanas, confirming that aldehydes are part of femoral 436 gland secretions. However, further research should clarify their potential role in intraspecific 437 communication. Alternatively, differences in chemical secretions between land and marine 438 iguanas could be due to their distinct diets. Marine iguanas live in humid coastal areas, and 439 adults dive to feed on algae (Trillmich \& Trillmich 1986). Conversely, land iguanas, are strictly 440 terrestrial, feeding mainly on Opuntia cactus and other terrestrial vegetation (Traveset et al. 441 2016). Therefore, it could be that interspecific differences in secretions are related to the 442 variation on feeding regimes between both species. Moreover, our results must be interpreted 443 carefully because land iguanas were kept in captivity and this could affect their diet as well. 444 Therefore, we cannot rule out that the differences on chemical secretions are plastic and a more 445 intensive sampling in natural populations should shed light on the divergence on gland chemistry 446 between both species.

447 In general terms, the femoral lipids present in A. cristatus are similar to those found in 448 other iguanids (Alberts et al. 1992), and are composed of ten carboxylic acids and three sterols. 449 The carboxylic acid chain lengths ranged between $\mathrm{C}_{16}$ and $\mathrm{C}_{24}$. The most abundant compound 450 was cholesterol. This sterol is also one of the most common compounds found in the femoral 451 glands of many other lizard species (Martín \& Lopez 2014). Cholesterol is thought to play an 452 important role in stabilizing other molecules, such as fatty acids found in gland secretions 453 (Escobar et al. 2003; Weldon et al. 2008). This would be especially important in hot habitats, 454 such as those occupied by the marine iguanas, where high temperatures may contribute to the 455 rapid degradation of chemical signals; therefore cholesterol could act as a protector of other 456 compounds with potential pheromone activity. However, the chemical composition of the 
457 femoral glands varies greatly among populations of marine iguanas across the archipelago. For 458 example, cholesterol accounted for almost $40 \%$ of the gland secretions in marine iguanas from 459 Isabela and Santa Cruz, but was less than $20 \%$ of secretions from Pinta and Española iguanas.

460 Other compounds, such as 11- and 13-eicosenoic acids, were absent in some of the northern 461 islands (Marchena, Pinta, Genovesa), as well as in Santa Fe and northern San Cristóbal, but were 462 present in low proportions in the rest of the islands. Eicosenoic acids have been reported in green 463 iguanas but their relative amounts are much higher (1.4\%) than in marine iguanas (0.4\%). Such 464 differences in secretions of both species could arise to distinct ecological or microclimatic 465 conditions between both species, however, more research is needed to confirm this hypothesis. 466 Similarly, other studies on Mediterranean lizards showed high variation among island 467 populations within the same species. For instance, populations of the Balearic lizard Podarcis 468 lilfordi from different islets showed strong differences in the lipid composition of their femoral 469 secretions (Martín et al. 2013). Further, a study comparing gland chemistry of different 470 populations of the Skyros wall lizard (Podarcis gaigeae), found that islet populations diverged 471 considerably more than mainland populations (Runemark et al. 2011). However, contrary to the 472 latter study, which suggested that chemical profile variation reflects genetic differentiation 473 between populations, the observed variation in marine iguana lipid profiles does not correlate 474 with the underlying genetic population structure and ongoing differentiation/speciation 475 processes. Based on analysis of microsatellite loci, most islands of the archipelago harbour a 476 distinct genetic cluster of marine iguanas, with some exceptions where islands share a cluster 477 (MacLeod et al. 2015). This is the case for iguanas from Española and Floreana, as well as for 478 the populations from Isabela and Fernandina. In our study, the chemical signatures of the iguanas 479 from these islands differed statistically. Moreover, a remarkable peculiarity of the genetic 480 structure of marine iguanas is found in the island of San Cristóbal, where two genetically distinct 481 subspecies are in an ongoing speciation process within the same island (MacLeod et al. 2015; 482 Miralles et al. 2017). One of the most important mechanisms driving speciation through 483 chemical signals is a mutation in a receptor that switches the specificity for a given pheromone 484 compound (Leary et al. 2012). This process promotes the development of divergent pheromones, 485 thereby establishing pre-mating barriers and precluding gene flow between populations. 486 However, we found no evidence that the ongoing speciation process in the marine iguanas of San 487 Cristóbal is reflected in the variation of lipophilic compounds. The femoral secretions of the two 
488 main colonies of the distinct genetic clusters, i.e. La Lobería and Punta Pitt, have similar 489 chemical profiles. We therefore conclude that the profiles of lipophilic substances do not 490 correlate with the genetic diversity of populations and therefore, lipophilic compounds might 491 play only a minor role in prezygotic isolation between marine iguana populations. However, the 492 role that different compounds have is still unknown. It could be that small amounts in specific 493 compounds could play a role in keeping both populations apart. For example, 11- and 13494 eicosenoic acids were present in very small amounts in La Lobería colony but not in Punta Pitt, 495 and it could contribute to maintain reproductive isolation between them. Alternatively, among496 population differences in femoral secretions could be related to distinct diets. It is known that 497 dietary lipids can result in concomitant alterations of the lipid composition of important tissues 498 (Simandle et al. 2001). Marine iguanas are specialized on feeding macrophytic algae (Trillmich 499 and Trillmich 1986; Wikelski et al. 1993) and it could possible that the different islands vary in

500 the amount of grazable algae leading to the observed difference in chemical composition of 501 femoral glands.

\section{Behavioural and functional correlates of lipophilic compounds}

504 We found that marine iguanas with better body condition had higher amounts of 11-eicosenoic acid and tetracosanoic acid (see Fig. 4). Saturated and unsaturated fatty acids, such as 11eicosenoic acid and tetracosanoic acid, are part of the energetic dietary lipids and fat stores of lizards (Geiser \& Learmonth 1994; Simandle et al. 2001). Therefore, femoral secretions rich in 11-eicosenoic acid and tetracosanoic acid might reflect male fat reserves, suggesting that only marine iguanas in an optimal body condition can afford to allocate these lipids to their femoral glands. Further support for this hypothesis comes from the fact that the presence of females in

511 leks correlates with levels of 11-eicosenoic acid in the territorial male's secretions. Male iguanas

512 that had 11-eicosenoic acid in their secretions had a higher head bobbing rate when compared to 513 those that lacked this compound, though the effect was only marginal. Female marine iguanas 514 choose territorial males for mating on the basis of their head bobbing behaviour - the greater the 515 investment in the display, the higher the reproductive success of the males (Vitousek et al. 2008). 516 Thus, dominant males may also enhance their mating probability by releasing high amounts of

517 11-eicosenoic acid within their territories. Evidence to support this idea is provided by other 518 reptile studies which show that unsaturated fatty acids may function as sexual attractors. For 
519 instance, male rock lizards Iberolacerta cyreni produce scent marks with more oleic acid to 520 attract females and thereby increase their mating opportunities (Martín \& Lopez 2010). A similar 521 mechanism is likely to occur in the lek-mating system of marine iguanas, where scent marking 522 would be essential in order to establish male territories (Partecke et al. 2002; Wikelski et al. 523 1996). Therefore, the results of this study suggest the presence of an underlying mechanism, 524 whereby scent marks are produced by males to increase their mating opportunities and therefore 525 their reproductive success. In order to attract females to their own territories, males would 526 provide reliable information on their condition by the allocation of more 11-eicosenoic acid in 527 their femoral gland secretions. However, other compounds such as docosanoic acid and 13528 eicosenoic acid were strongly related to tetracosanoic acid and 11-eicosenoic acid respectively, 529 and thus, could be that these compounds are also involved in intraspecific communication. 530 Therefore, our results must be carefully interpreted because other compounds are also good 531 pheromone candidates. Docosanoic acid and especially 13-eicosenoic acid are compounds that 532 should be investigated in future studies to test whether they play role in marine iguana chemical 533 communication. Moreover, further experimental research is needed to understand how female 534 marine iguanas use the information contained in male gland secretions. An experiment testing 535 female response to different concentrations of 11-eicosenoic acids could elucidate whether such 536 compound is a pheromone involved in mate choice.

537

\section{CONCLUSIONS}

539

540 Evolutionary divergence between land and marine iguanas is reflected by a remarkable

541 divergence of lipophilic substances that might have altered in response to environmental 542 constraints and the different life histories of both species. Differences in composition of 543 lipophilic substances seem not to be of central importance for the maintenance of genetic 544 population structure, or for the ongoing differentiation and speciation processes in marine 545 iguanas. However, males might use certain compounds, such as fatty acids like 11-eicosenoic 546 and tetracosanoic acids to signal a good body condition and to successfully attract females for 547 lek-mating. The composition and type of lipophilic substances in the femoral secretions of 548 marine iguanas seem to be more influenced by habitat conditions than by genetic differentiation. 


\section{ACKNOWLEDGEMENTS}

551 We want to thank Marcus Krüger, M. Dolores Astudillo and Rocío Ruiz for their support in the field.We are grateful 552 for the constructive comments provided by three referees. This publication is contribution number 2173 of the 553 Charles Darwin Foundation for the Galápagos Islands.

\section{REFERENCES}

Alberts AC. 1991. Phylogenetic and adaptive variation in lizard femoral gland secretions. Copeia:69-79.

558 Alberts AC. 1989. Ultraviolet visual sensitivity in desert iguanas: implications for pheromone detection. Animal Behaviour 38:129-137.

Alberts AC. 1990. Chemical properties of femoral gland secretions in the desert iguana, Dipsosaurus dorsalis. Journal of Chemical Ecology 16:13-25.

562 Alberts A. 1993. Chemical and Behavioral Studies of Femoral Glad Secretions in Iguanid Lizards. Brain, Behavior and Evolution 41:255-260. Alberts AC, Pratt NC, and Phillips JA. 1992. Seasonal productivity of lizard femoral glands: relationship to social dominance and androgen levels. Physiology \& Behavior 51:729-733.Apps PJ, Weldon PJ, and Kramer M. 2015. Chemical signals in terrestrial vertebrates: search for design features. Natural Product Reports 32:1131-1153. Miralles A, Macleod A, Rodríguez A, Ibáñez A, Jiménez-Uzcategui G, Quezada G, Vences M, Steinfartz S. 2017. Shedding light on the Imps of Darkness: an integrative taxonomic revision of the Galápagos marine iguanas (genus Amblyrhynchus). Zoological Journal of the Linnean Society XX:1-33. doi: 10.1093/zoolinnean/zlx007 Bates D, Maechler M, Bolker B, and Walker S. 2014. lme4: Linear mixed-effects models using Eigen and S4. $R$ package version 1 .

572 Benjamini Y, and Hochberg Y. 1995. Controlling the false discovery rate: a practical and powerful approach to multiple testing. Journal of the royal statistical society Series B (Methodological):289-300. Black TH. 1983. The preparation and reactions of diazomethane. Chemischer Informationsdienst 14.

575 Bruns H, Thiel V, Voget S, Patzelt D, Daniel R, Wagner-Döbler I, and Schulz S. 2013. N-Acylated Alanine Methyl 576 Esters (NAMEs) from Roseovarius tolerans, Structural Analogs of Quorum-Sensing Autoinducers, 577 N-Acylhomoserine Lactones. Chemistry \& Biodiversity 10:1559-1573.

578 Buser HR, Arn H, Guerin P, and Rauscher S. 1983. Determination of double bond position in mono-unsaturated 579 acetates by mass spectrometry of dimethyl disulfide adducts. Analytical Chemistry 55:818-822.

580 Cabrera M, and Jaffe K. 2007. An aggregation pheromone modulates lekking behavior in the vector mosquito Aedes 581 aegypti (Diptera: Culicidae). Journal of the American Mosquito Control Association 23:1-10.

582 Calcagno V. 2013. glmulti: Model selection and multimodel inference made easy. R package version 1.

583 Carazo P, Font E, and Desfilis E. 2008. Beyond 'nasty neighbours' and 'dear enemies'? Individual recognition by 584 scent marks in a lizard (Podarcis hispanica). Animal Behaviour 76:1953-1963. 
585 Carpenter CC. 1966. The marine iguana of the Galapagos Islands: its behavior and ecology. Proceedings of 586 the California Academy of Natural Sciences, 34:329-376.

587 De Fazio A, Simon CA, Middendorf GA, and Romano D. 1977. Iguanid substrate licking: a response to novel 588 situations in Sceloporus jarrovi. Copeia:706-709.

589 Dormann CF, Elith J, Bacher S, Buchmann C, Carl G, Carré G, Marquéz JRG, Gruber B, Lafourcade B, and Leitão

590 PJ. 2013. Collinearity: a review of methods to deal with it and a simulation study evaluating their performance.

591 Ecography 36:27-46.

592 Escobar CM, Escobar CA, Labra A, and Niemeyer HM. 2003. Chemical composition of precloacal secretions of two

593 Liolaemus fabiani populations: are they different? Journal of Chemical Ecology 29:629-638.

594 Fergusson B, Bradshaw S, and Cannon J. 1985. Hormonal control of femoral gland secretion in the lizard, 595 Amphibolurus ornatus. General and Comparative Endocrinology 57:371-376.

596 García-Roa R, Jara M, López P, Martín J, and Pincheira-Donoso D. 2017. Heterogeneous tempo and mode of 597 evolutionary diversification of compounds in lizard chemical signals. Ecology and Evolution 7:1286-1296.

598 Geiser F, and Learmonth R. 1994. Dietary fats, selected body temperature and tissue fatty acid composition of 599 agamid lizards (Amphibolurus nuchalis). Journal of Comparative Physiology B 164:55-61.

600 Heathcote RJ, Bell E, d'Ettorre P, While GM, and Uller T. 2014. The scent of sun worship: basking experience

601 alters scent mark composition in male lizards. Behavioral Ecology and Sociobiology, 68:861-870.

602 Higgins P. 1978. The Galápagos Iguanas: Models of Reptilian Differentiation. BioScience 28:512-515.

603 Höglund J, and Alatalo R. 1995. Leks Princeton University Press-Princeton. New Jersey.

604 Jones TM, and Hamilton J. 1998. A role for pheromones in mate choice in a lekking sandfly. Animal Behaviour 605 56:891-898.

606 Khannoon ER, El-Gendy A, and Hardege JD. 2011. Scent marking pheromones in lizards: cholesterol and long 607 chain alcohols elicit avoidance and aggression in male Acanthodactylus boskianus (Squamata: Lacertidae). 608 Chemoecology 21:143-149.

609 Krebs CJ, and Singleton GR. 1993. Indexes of condition for small mammals. Australian Journal of Zoology 41:317610323.

611 Krekorian CN. 1989. Field and laboratory observations on chemoreception in the desert iguana, Dipsosaurus 612 dorsalis. Journal of Herpetology:267-273.

613 Lanterbecq D, Glaberman S, Vitousek MN, Steinfartz S, Benavides E, Wikelski M, and Caccone A. 2010. Genetic 614 differentiation between marine iguanas from different breeding sites on the island of Santa Fe (Galápagos 615 Archipelago). Journal of Heredity, 101:663-675.

616 Leary GP, Allen JE, Bunger PL, Luginbill JB, Linn CE, Macallister IE, Kavanaugh MP, and Wanner KW. 2012.

617 Single mutation to a sex pheromone receptor provides adaptive specificity between closely related moth species.

618 Proceedings of the National Academy of Sciences 109:14081-14086.

619 LeMaster MP, and Mason RT. 2003. Pheromonally mediated sexual isolation among denning populations of red620 sided garter snakes, Thamnophis sirtalis parietalis. Journal of Chemical Ecology 29:1027-1043. 
621 López P, and Martín J. 2005. Female Iberian wall lizards prefer male scents that signal a better cell-mediated 622 immune response. Biology Letters 1:404-406.

623 López P, and Martín J. 2009. Lipids in femoral gland secretions of male lizards, Psammodromus hispanicus.

624 Biochemical Systematics and Ecology 37:304-307.

625 MacLeod A, Rodríguez A, Vences M, Orozco-terWengel P, García C, Trillmich F, Gentile G, Caccone A, Quezada

626 G, and Steinfartz S. 2015. Hybridization masks speciation in the evolutionary history of the Galápagos marine 627 iguana. Proceedings of the Royal Society of London Series B-Biological Sciences 282:20150425.

628 MacLeod A, Unsworth L, Trillmich F, and Steinfartz S. 2016. Mark-resight estimates confirm a critically small 629 population size in threatened marine iguanas (Amblyrhynchus cristatus) on San Cristóbal Island, Galápagos.

630 Salamandra 52: 58-62.

631 Martín J, and López P. 2006. Links between male quality, male chemical signals, and female mate choice in Iberian 632 Rock Lizards. Functional Ecology 20:1087-1096.

633 Martín J, and López P. 2006. Age-related variation in lipophilic chemical compounds from femoral gland secretions 634 of male lizards Psammodromus algirus. Biochemical Systematics and Ecology 34:691-697.

635 Martín J, and López P. 2010. Condition-dependent pheromone signaling by male rock lizards: more oily scents are 636 more attractive. Chemical Senses 35:253-262.

637 Martín J, and López P. 2011. Pheromones and reproduction in reptiles. In: Norris DO \& Lopez KH (Eds) Hormones 638 and reproduction in vertebrates-reptiles: Academic Press, San Diego, pp 141-167

639 Martín J, and López P. 2014. Pheromones and chemical communication in lizards. In: Rheubert JL, Siegel DS \& 640 Trauth SE (Eds) Reproductive Biology and Phylogeny of Lizards and Tuatara: CRC Press, Boca Raton, Florida, 641 USA.

642 Martín J, López P, Garrido M, Pérez-Cembranos A, and Pérez-Mellado V. 2013. Inter-island variation in femoral 643 secretions of the Balearic lizard, Podarcis lilfordi (Lacertidae). Biochemical Systematics and Ecology 50:121-128.

644 Martín J, Martínez-Silvestre A, López P, Ibánez A, Rodríguez-Domínguez MÁ, and Verdaguer I. (2015). Lipophilic

645 compounds in femoral secretions of males and females of the El Hierro giant lizard Gallotia simonyi (Lacertidae).

646 Biochemical Systematics and Ecology, 61:286-292.

647 Martins E, Ord T, Slaven J, Wright J, and Housworth E. 2006. Individual, sexual, seasonal, and temporal variation 648 in the amount of sagebrush lizard scent marks. Journal of Chemical Ecology 32:881-893.

649 Mason RT, and Parker MR. 2010. Social behavior and pheromonal communication in reptiles. Journal of 650 Comparative Physiology A 196:729-749.

651 Mayerl C, Baeckens S, and Van Damme R. 2015. Evolution and role of the follicular epidermal gland system in 652 non-ophidian squamates. Amphibia-Reptilia 36:185-206.

653 Moreira PL, López P, and Martín J. 2006. Femoral secretions and copulatory plugs convey chemical information 654 about male identity and dominance status in Iberian rock lizards (Lacerta monticola). Behavioral Ecology and 655 Sociobiology 60:166-174. 
656 Olsson M, Madsen T, Nordby J, Wapstra E, Ujvari B, and Wittsell H. 2003. Major histocompatibility complex and 657 mate choice in sand lizards. Proceedings of the Royal Society of London Series B-Biological Sciences 270:S254658 S256.

659 Oksanen J, Blanchet G, Kindt R, Minchin PR, Legendre P, O'Hara B, Simpson GL, Solymos P, Stevens MHH, and 660 Wagner H. 2011. vegan: Community Ecology Package. R Package Version 2.0-2.

661 Partecke J, von Haeseler A, and Wikelski M. 2002. Territory establishment in lekking marine iguanas, 662 Amblyrhynchus cristatus: support for the hotshot mechanism. Behavioral Ecology and Sociobiology 51:579-587.

663 Rauch N. 1988. Competition of marine iguana females (Amblyrhynchus cristatus) for egg-laying sites. 664 Behaviour:91-106.

665 Runemark A, Gabirot M, and Svensson E. 2011. Population divergence in chemical signals and the potential for 666 premating isolation between islet-and mainland populations of the Skyros wall lizard (Podarcis gaigeae). Journal of 667 Evolutionary Biology 24:795-809.

668 Shine R, Webb J, Lane A, and Mason R. 2005. Mate location tactics in garter snakes: effects of rival males, 669 interrupted trails and non-pheromonal cues. Functional Ecology 19:1017-1024.

670 Simandle ET, Espinoza RE, Nussear KE, and Tracy CR. 2001. Lizards, lipids, and dietary links to animal function. 671 Physiological and Biochemical Zoology 74:625-640.

672 Traveset A, Nogales M, Vargas P, Rumeu B, Olesen JM, Jaramillo P, and Heleno R. 2016. Galápagos land iguana 673 (Conolophus subcristatus) as a seed disperser. Integrative Zoology 11:207-213.

674 Trillmich F, and Trillmich KG. 1984. The mating systems of pinnipeds and marine iguanas: convergent evolution of 675 polygyny. Biological Journal of the Linnean Society 21:209-216.

676 Trillmich KG, and Trillmich F. 1986. Foraging strategies of the marine iguana, Amblyrhynchus cristatus. Behavioral 677 Ecology and Sociobiology 18:259-266.

678 Van den Dool H, and Kratz PD 1963. A generalization of the retention index system including linear temperature 679 programmed gas - liquid partition chromatography. Journal of Chromatography A 11:463-471.

680 Vitousek MN, Rubenstein DR, Nelson KN, and Wikelski M. 2008. Are hotshots always hot? A longitudinal study of 681 hormones, behavior, and reproductive success in male marine iguanas. General and Comparative Endocrinology $682157: 227-232$.

683 Welch ME, Colosimo G, Pasachnik SA, Malone CL, Hilton J, Long J, Getz AH, Alberts AC, and Gerber GP. 2017.

684 Molecular variation and population structure in critically endangered Turks and Caicos Rock Iguanas: identifying 685 intraspecific conservation units and revising subspecific taxonomy. Conservation Genetics 18:479-493.

686 Weldon PJ, Dunn BS, McDaniel CA, and Werner DI. 1990. Lipids in the femoral gland secretions of the green 687 iguana (Iguana iguana). Comparative Biochemistry and Physiology Part B: Comparative Biochemistry 95:541-543.

688 Weldon PJ, Flachsbarth B, and Schulz S. 2008. Natural products from the integument of nonavian reptiles. Natural 689 Product Reports 25:738-756.

690 Wikelski M, Gall B, and Trillmich F. 1993. Ontogenetic changes in food intake and digestion rate of the herbivorous 691 marine iguana (Amblyrhynchus cristatus, Bell). Oecologia 94: 373-379. 
692 Wikelski M, Carbone C, and Trillmich F. 1996. Lekking in marine iguanas: Female grouping and male reproductive 693 strategies. Animal Behaviour 52:581-596.

694 Wikelski M, and Romero LM. 2003. Body size, performance and fitness in Galapagos marine iguanas. Integrative 695 and Comparative Biology 43:376-386.

696 Wyatt TD. 2003. Pheromones and animal behaviour: communication by smell and taste: Cambridge University 697 Press. 
699 Table 1

700 Percentage (Mean \pm SD) of major compounds present in marine and land iguana secretions, with 701 the retention indices (RI) of methyl esters of the fatty acids and cholesterol derivatives. Retention 702 indices have been calculated using a method developed by Van den Dool and Kratz (1963). 703 Compounds specific for land iguanas have been given in bold (aldehydes are marked with an*). 704

\begin{tabular}{|c|c|c|c|}
\hline \multicolumn{2}{|c|}{ Lipids (Mean \pm SD) } & \multirow[b]{2}{*}{ Compound name } & \multirow[b]{2}{*}{$\mathrm{RI}$} \\
\hline Marine iguana & Land iguana & & \\
\hline- & $2.59 \pm 1.65$ & Hexadecanal* & 1813 \\
\hline- & $0.55 \pm 0.74$ & 7-Hexadecenoic acid & 1904 \\
\hline- & $1.48 \pm 1.08$ & 9-Hexadecenoic acid & 1908 \\
\hline $22.41 \pm 12.01$ & $19.99 \pm 12.19$ & Hexadecanoic acid & 1928 \\
\hline- & $0.48 \pm 0.83$ & 9-Octadecenal* & 1993 \\
\hline- & $0.27 \pm 0.47$ & 11-Octadecenal* & 1997 \\
\hline- & $0.59 \pm 0.67$ & Octadecanal* & 2016 \\
\hline- & $1.55 \pm 0.37$ & Di-(9-Octadecenoyl)-glycerol & 2473 \\
\hline $13.68 \pm 4.81$ & $20.40 \pm 12.34$ & 9-Octadecenoic acid & 2099 \\
\hline $1.45 \pm 1.25$ & $4.72 \pm 2.80$ & 11-Octadecenoic acid & 2104 \\
\hline $12.12 \pm 7.15$ & $8.37 \pm 4.21$ & Octadecanoic acid & 2125 \\
\hline $4.85 \pm 2.81$ & $1.92 \pm 1.06$ & 5,8,11,14-Eicosatetraenoic acid & 2258 \\
\hline $0.35 \pm 1.01$ & $0.26 \pm 0.15$ & 11-Eicosenoic acid & 2299 \\
\hline $0.1 \pm 0.23$ & - & 13-Eicosenoic acid & 2306 \\
\hline $3.43 \pm 2.58$ & $0.55 \pm 0.31$ & Eicosanoic acid & 2326 \\
\hline $2.41 \pm 1.75$ & $0.47 \pm 0.16$ & Docosanoic acid & 2501 \\
\hline $2.13 \pm 1.66$ & $0.55 \pm 0.37$ & Tetracosanoic acid & 2536 \\
\hline $31.14 \pm 13.14$ & $29.67 \pm 31.81$ & Cholesterol & 3133 \\
\hline $4.73 \pm 4.46$ & $0.11 \pm 0.19$ & Cholestanol & 3143 \\
\hline $1.11 \pm 1.39$ & $1.32 \pm 0.75$ & Cholestanone & 3187 \\
\hline- & $4.11 \pm 5.3$ & Hexadecyl hexadecanoate & 3361 \\
\hline
\end{tabular}


705 Table 2

706 Percentage (Mean \pm SD) of the lipophilic compounds indentified and quantified in the distinct

707 populations of marine iguanas (A. cristatus). Most influential compounds contributing to

708 dissimilarity among populations (SIMPER analysis) are marked in bold. Abbreviations for the

709 populations: IS=Isabela, MAR=Marchena, PIN=Pinta, GEN=Genovesa, SAN=Santiago,

$710 E S P=$ Española $, F L=F l o r e a n a, S F E=$ Santa Fe, FDA=Fernandina, CRUZ=Santa Cruz, SRL=

711 San Cristóbal (La Lobería), SRPC= San Cristóbal (Punta Pitt).

712

\begin{tabular}{|c|c|c|c|c|c|c|c|c|c|c|c|c|}
\hline & $I S$ & $M A R$ & $P I N$ & $G E N$ & $S A N$ & $E S P$ & $F L$ & $S F E$ & $F D A$ & $C R U Z$ & $\overline{S R L}$ & $S R P C$ \\
\hline \multirow{2}{*}{$\begin{array}{l}\text { Hexadecanoic } \\
\text { acid }\end{array}$} & $13.17 \pm$ & $29.17 \pm$ & $38.47 \pm$ & $32.45 \pm$ & $29.68 \pm$ & $38.77 \pm$ & $11.51 \pm$ & $24.29 \pm$ & $18.91 \pm$ & $14.92 \pm$ & $15.84 \pm$ & $21.46 \pm$ \\
\hline & 2.48 & 15.15 & 13.07 & 16.63 & 7.82 & 9.79 & 2.41 & 8.72 & 3.15 & 2.95 & 3.15 & 12.49 \\
\hline \multirow{2}{*}{$\begin{array}{l}\text { 9-Octadecenoic } \\
\text { acid }\end{array}$} & $14.61 \pm$ & $12.48 \pm$ & $8.83 \pm$ & $12.52 \pm$ & $13.08 \pm$ & $17.53 \pm$ & $12.07 \pm$ & $15.73 \pm$ & $13.68 \pm$ & $15.16 \pm$ & $11.05 \pm$ & $15.16 \pm$ \\
\hline & 2.53 & 6.61 & 8.43 & 5.99 & 4.54 & 4.50 & 1.75 & 3.03 & 2.27 & 2.10 & 6.42 & 5.90 \\
\hline \multirow{4}{*}{$\begin{array}{l}\text { 11- } \\
\text { Octadecenoic } \\
\text { acid } \\
\text { Octadecanoic } \\
\text { acid }\end{array}$} & $2.60 \pm$ & $0.61 \pm$ & $0.00 \pm$ & $0.00 \pm$ & $1.98 \pm$ & $0.32 \pm$ & $1.94 \pm$ & $0.70 \pm$ & $2.03 \pm$ & $2.05 \pm$ & $2.59+$ & $0.87 \pm$ \\
\hline & 0.65 & 0.95 & 0 & 0 & 1.89 & 0.90 & 0.68 & 1.07 & 0.79 & 0.36 & 0.96 & 0.94 \\
\hline & $7.98 \pm$ & $17.42 \pm$ & $22.07 \pm$ & $16.24 \pm$ & $14.28 \pm$ & $19.80 \pm$ & $6.77 \pm$ & $10.61 \pm$ & $10.78 \pm$ & $8.32 \pm$ & $8.90+$ & $12.75 \pm$ \\
\hline & 1.42 & 13.11 & 13.69 & 7.76 & 4.04 & 5.85 & 1.08 & 2.89 & 1.88 & 1.41 & 1.06 & 8.91 \\
\hline \multirow{4}{*}{$\begin{array}{l}5,8,11,14- \\
\text { Eicosatetraenoi } \\
\text { c acid } \\
\text { 11-Eicosenoic } \\
\text { acid }\end{array}$} & $5.76 \pm$ & $4.49 \pm$ & $3.39 \pm$ & $2.10 \pm$ & $3.53 \pm$ & $4.47 \pm$ & $4.94 \pm$ & $3.28 \pm$ & $6.28 \pm$ & $6.04 \pm$ & $6.26+$ & $5.23 \pm$ \\
\hline & 1.01 & 3.73 & 4.55 & 3.59 & 2.52 & 4.92 & 0.81 & 3.16 & 1.02 & 0.84 & 1.21 & 2.95 \\
\hline & $1.00 \pm$ & $0.00 \pm$ & $0.00 \pm$ & $0.00 \pm$ & $0.12 \pm$ & $1.20 \pm$ & $0.39 \pm$ & & $0.08 \pm$ & $0.62 \pm$ & $0.51+$ & \\
\hline & 0.24 & $\mathbf{0}$ & $\mathbf{0}$ & 0 & 0.31 & 3.39 & 0.35 & $\mathbf{0 . 0 0} \pm \mathbf{0}$ & 0.28 & 0.45 & 0.38 & $0.00 \pm 0$ \\
\hline \multirow{2}{*}{$\begin{array}{l}\text { 13-Eicosenoic } \\
\text { acid }\end{array}$} & $0.59 \pm$ & $0.00 \pm$ & $0.00 \pm$ & $0.00 \pm$ & $0.08 \pm$ & $0.00 \pm$ & $0.19 \pm$ & & $0.00 \pm$ & $0.19 \pm$ & $0.04+$ & \\
\hline & 0.24 & 0 & 0 & $\mathbf{0}$ & 0.22 & $\mathbf{0}$ & 0.27 & $0.00 \pm 0$ & $\mathbf{0}$ & 0.24 & 0.13 & $0.00 \pm 0$ \\
\hline \multirow[t]{2}{*}{ Eicosanoic acid } & $2.75 \pm$ & $3.68 \pm$ & $2.36 \pm$ & $1.58 \pm$ & $6.56 \pm$ & $6.23 \pm$ & $2.80 \pm$ & $1.35 \pm$ & $4.12 \pm$ & $3.11 \pm$ & $3.57+$ & $3.30 \pm$ \\
\hline & 0.57 & 3.09 & 3.30 & 2.91 & 2.09 & 5.06 & 1.52 & 2.04 & 1.05 & 0.5 & 0.82 & 2.11 \\
\hline \multirow{2}{*}{$\begin{array}{l}\text { Docosanoic } \\
\text { acid }\end{array}$} & $1.94 \pm$ & $2.39 \pm$ & $2.14 \pm$ & $0.48 \pm$ & $3.91 \pm$ & $1.94 \pm$ & $3.12 \pm$ & $1.85 \pm$ & $2.82 \pm$ & $2.29 \pm$ & $2.71+$ & $2.87 \pm$ \\
\hline & 0.34 & 2.75 & 2.95 & 1.27 & 2.12 & 2.90 & 0.58 & 2.21 & 0.80 & 0.33 & 0.68 & 1.87 \\
\hline \multirow{2}{*}{$\begin{array}{l}\text { Tetracosanoic } \\
\text { acid }\end{array}$} & $1.81 \pm$ & $1.98 \pm$ & $0.87 \pm$ & $0.58 \pm$ & $4.02 \pm$ & $1.49 \pm$ & $2.76 \pm$ & $1.28 \pm$ & $2.57 \pm$ & $2.14 \pm$ & $2.91+$ & $2.35 \pm$ \\
\hline & 0.28 & 2.27 & 1.96 & 1.55 & 2.01 & 2.80 & 0.48 & 1.92 & 0.68 & 0.36 & 0.88 & 1.79 \\
\hline \multirow[t]{2}{*}{ Cholesterol } & $38.50 \pm$ & $23.54 \pm$ & $21.93 \pm$ & $32.59 \pm$ & $18.03 \pm$ & $8.23 \pm$ & $40.41 \pm$ & $34.49 \pm$ & $33.18 \pm$ & $39.56 \pm$ & $37.65 \pm$ & $29.98 \pm$ \\
\hline & 5.68 & 13.93 & 14.11 & 16.21 & 6.01 & 9.22 & 5.12 & 6.28 & 6.08 & 6.61 & 8.17 & 16.25 \\
\hline \multirow[t]{2}{*}{ Cholestanol } & $7.85 \pm$ & $3.86 \pm$ & $0.00 \pm$ & $1.42 \pm$ & $4.56 \pm$ & $0.00 \pm$ & $10.53 \pm$ & $6.20 \pm$ & $4.32 \pm$ & $4.01 \pm$ & $5.45 \pm$ & $4.06 \pm$ \\
\hline & 1.93 & 6.30 & 0 & 3.7 & 6.48 & 0 & 1.96 & 5.97 & 3.76 & 2.08 & 2.60 & 2.56 \\
\hline \multirow[t]{2}{*}{ Cholestanone } & $1.41 \pm$ & $0.36 \pm$ & $0.00 \pm$ & $0.00 \pm$ & $0.15 \pm$ & $0.00 \pm$ & $2.54 \pm$ & $0.34 \pm$ & $1.21 \pm$ & $1.56 \pm$ & $2.51 \pm$ & $1.96 \pm$ \\
\hline & 0.58 & 0.89 & 0 & 0 & 0.39 & 0 & 1.02 & 1.03 & 1.06 & 0.74 & 1.31 & 2.41 \\
\hline
\end{tabular}

713

714

715

716 


\section{Table 3}

718 Top five ranked models that examined the probability that presence of females in a specific

719 male's territory depends on the chemical composition of its femoral secretions. AICc=AIC

720 corrected for small sample sizes; ER=Evidence Ratio. The best model is shown in bold.

721

722

Probability of having females in male's own territory

Variables included in the model

AICc Delta Weight ER

11-Eicosenoic acid

11-Eicosenoic acid + Tetracosanoic acid

$\begin{array}{llll}36.54 & 0 & 0.36 & 1.00\end{array}$

11-Eicosenoic acid +9-Octadecenoic acid

$\begin{array}{llll}37.82 & 1.28 & 0.19 & 1.90\end{array}$

11-Eicosenoic acid + Hexadecanoic acid

$\begin{array}{llll}38.36 & 0.54 & 0.14 & 1.31\end{array}$

11-Eicosenoic acid + Tetracosanoic acid + Hexadecanoic acid

$38.94 \quad 0.57 \quad 0.11$

39.93

1

0.06

1.64 
724 Figure caption:

725

726

Fig. 1

727 Map of the Galápagos Archipelago, showing the total number of femoral gland samples collected

728 per island, and the number of samples considered for statistical analysis in brackets. Island

729 abbreviations: GEN, Genovesa; MAR, Marchena; PIN, Pinta; SAN, Santiago; CRUZ, Santa

730 Cruz; SRL, San Cristóbal (La Lobería ); SRPC, San Cristóbal (Punta Pitt ); SFE, Santa Fe; ESP,

731 Española; FL, Floreana; IS, Isabela; FDA, Fernandina.

732

733 Fig. 2

734 Example of a chromatogram of marine iguana (SRL population). Each number correspond with 735 one of the identified compounds. $1=$ Hexadecanoic acid; $2=9$-Octadecenoic acid; $3=11$ -

736 Octadecenoic acid; 4 = Octadecanoic acid; $5=5,8,11,14$-Eicosatetraenoic acid; $6=11$ -

737 Eicosenoic acid; $7=13$-Eicosenoic acid; $8=$ Eicosanoic acid; $9=$ Docosanoic acid, $10=$

738 Tetracosanoic acid; $11=$ Cholesterol; $12=$ Cholestanol; $13=$ Cholestanone.

739

$740 \quad$ Fig. 3

741 a) Amount (percentage) of each chemical compound for all the sampled populations of marine

742 iguanas. Each colour represents one chemical compound.

743 b) Chemical composition plot, showing two-dimensional non-metric Multidimensional Scaling 744 (nMDS), which is based on the Bray-Curtis Similarity indices as calculated with metaMDS (in R;

745 using the vegan package). The closer the data point, the more similar the compound. Ellipses

746 represent $\mathrm{CI}=95 \%$.

747

748

Fig. 4

749 Plot showing the relation between male body condition and the amount of a) 11-eicosenoic acid 750 and b) tetracosanoic acid. In grey $95 \% \mathrm{CI}$.

751

752 Fig. 5

753 Plot showing the probability of the presence of females in male territories compared to the

754 amount of 11-eicosenoic acid. In grey $95 \% \mathrm{CI}$. 
755

756 Fig. 6

757 Box plot showing the head bobbing rate (Median \pm Q1 and Q3) as a function of the presence or 758 absence of 11-eicosenoic acid. 
$760 \quad$ Fig. 1

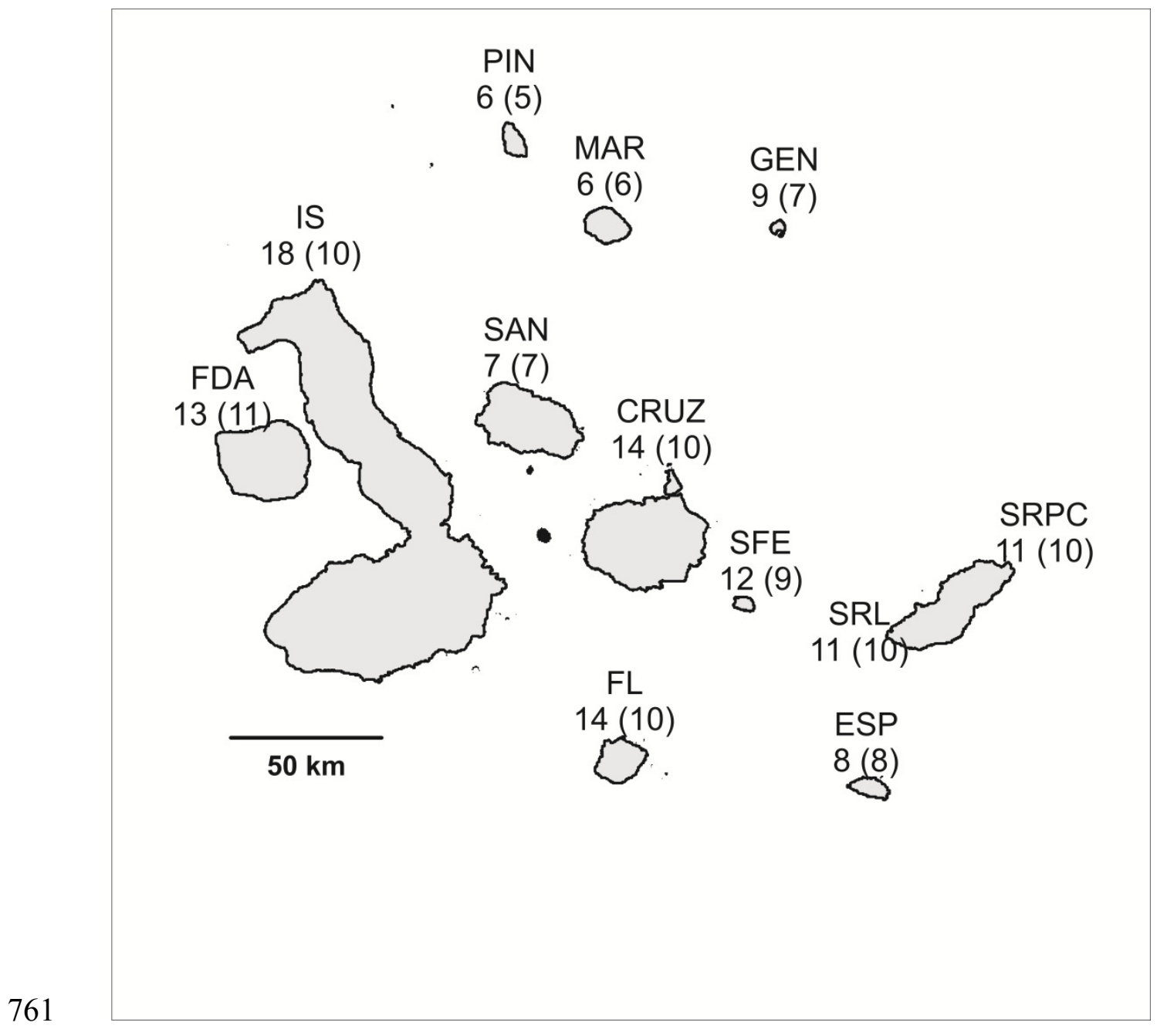


763 Fig. 2

764

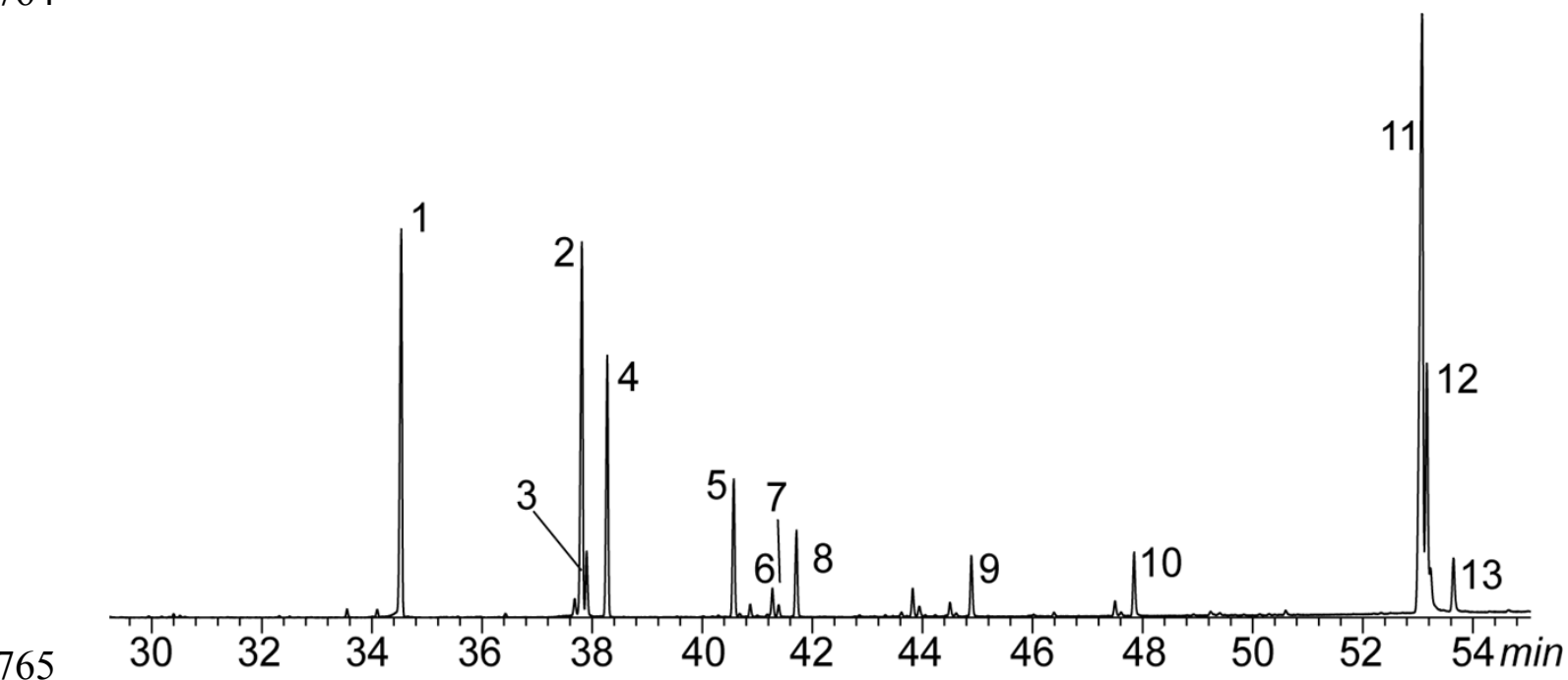


766 Fig. 3

767

768 a)

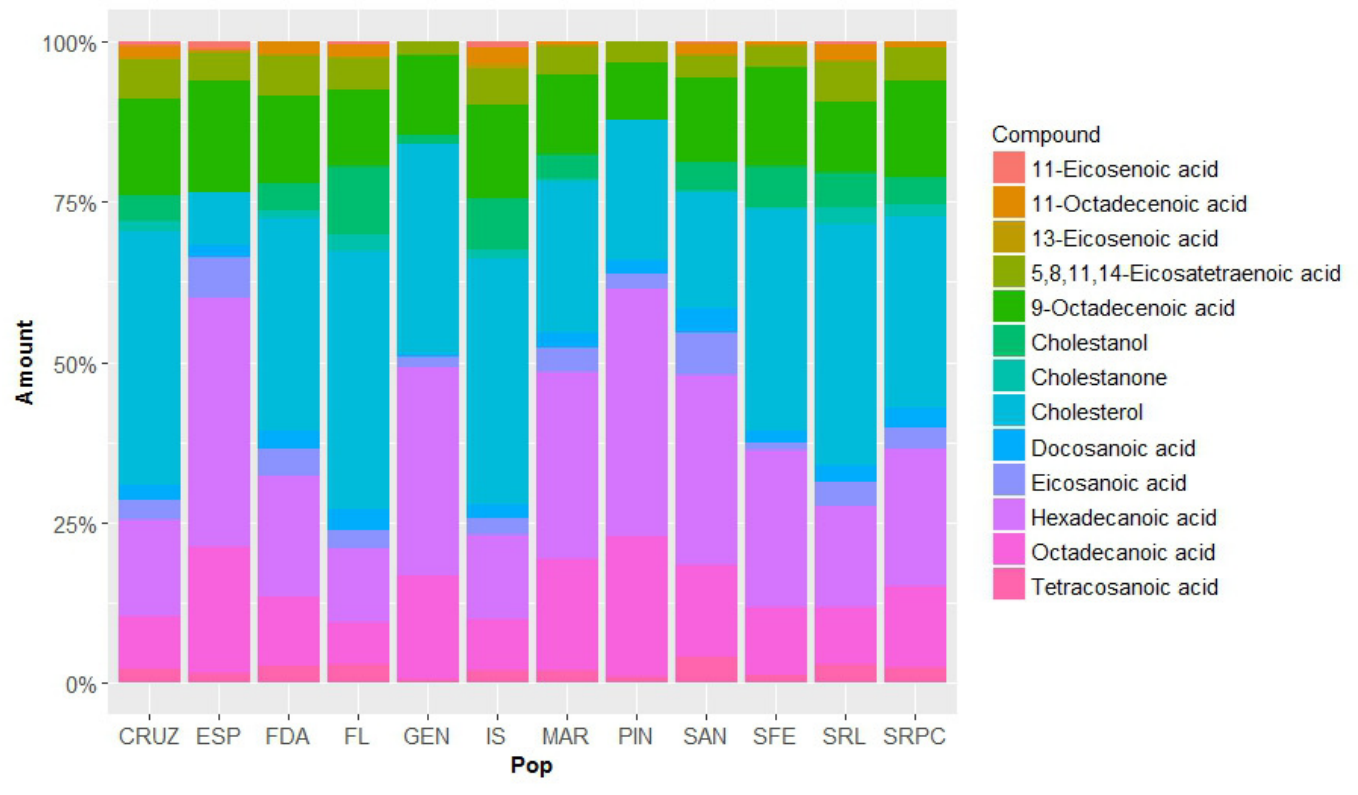

770 b)

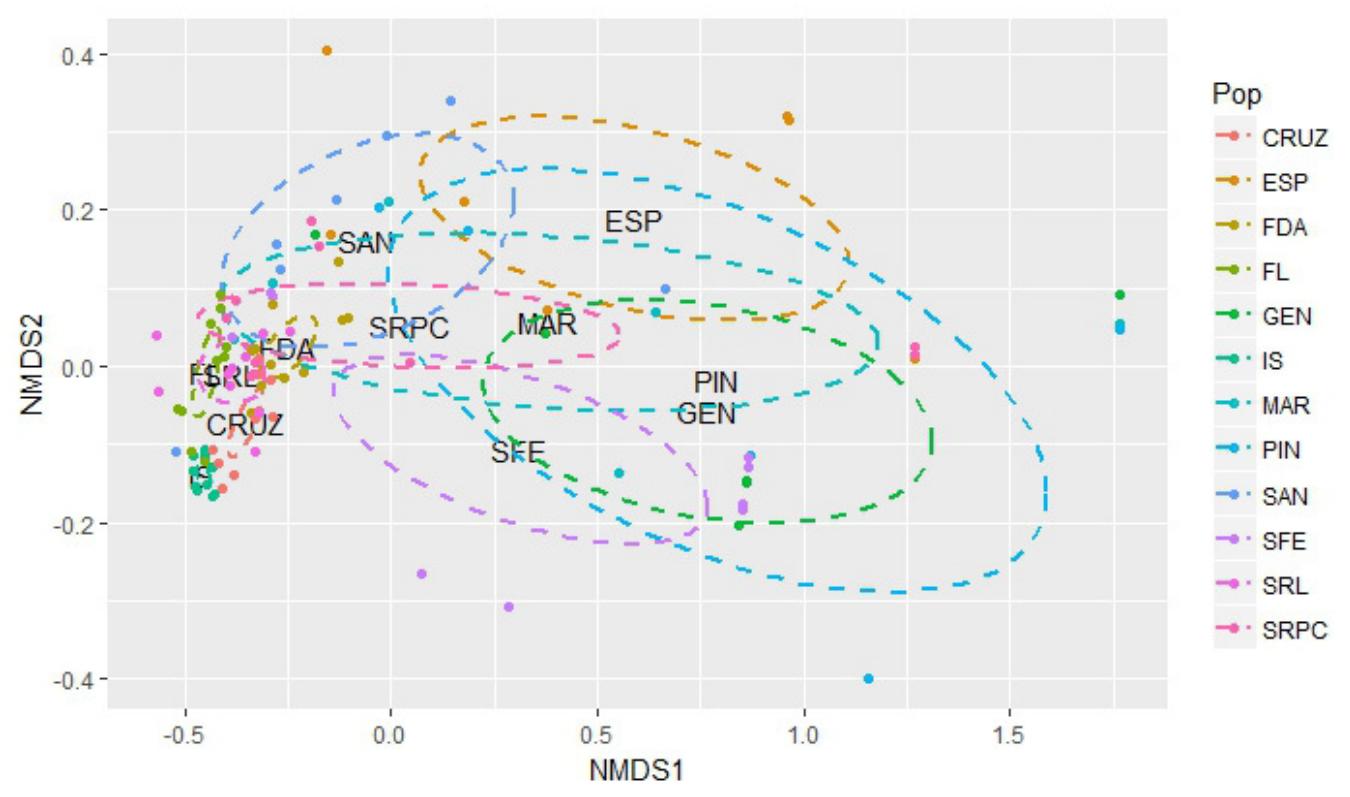




\section{Fig. 4}

775 a)

776

777

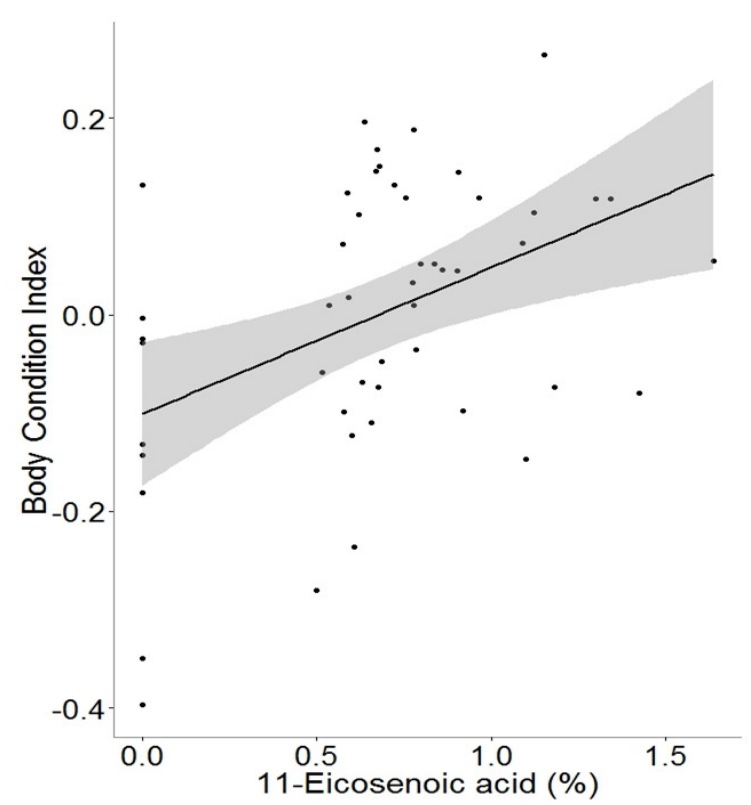

b)

778

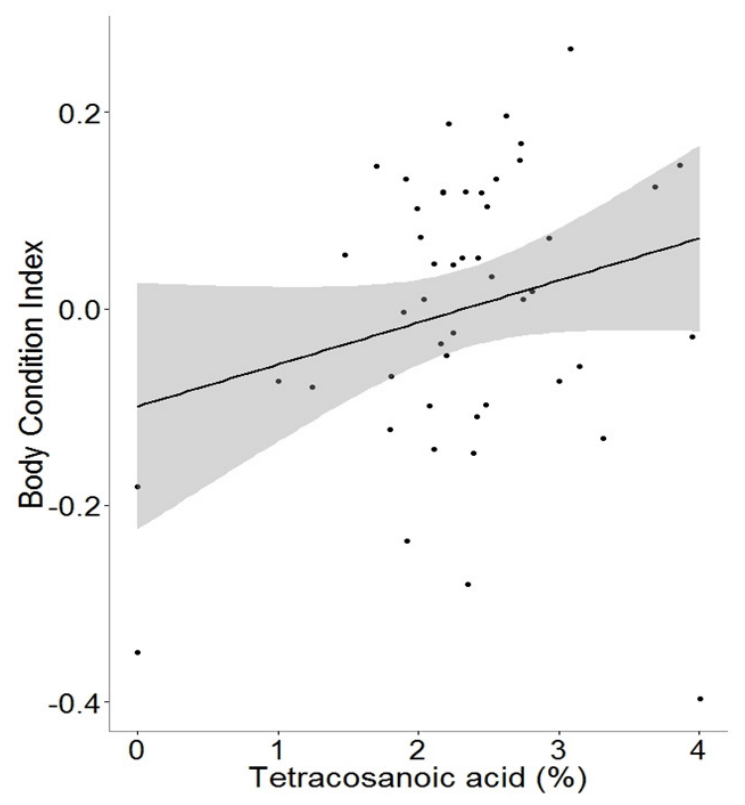

779 
780 Fig. 5

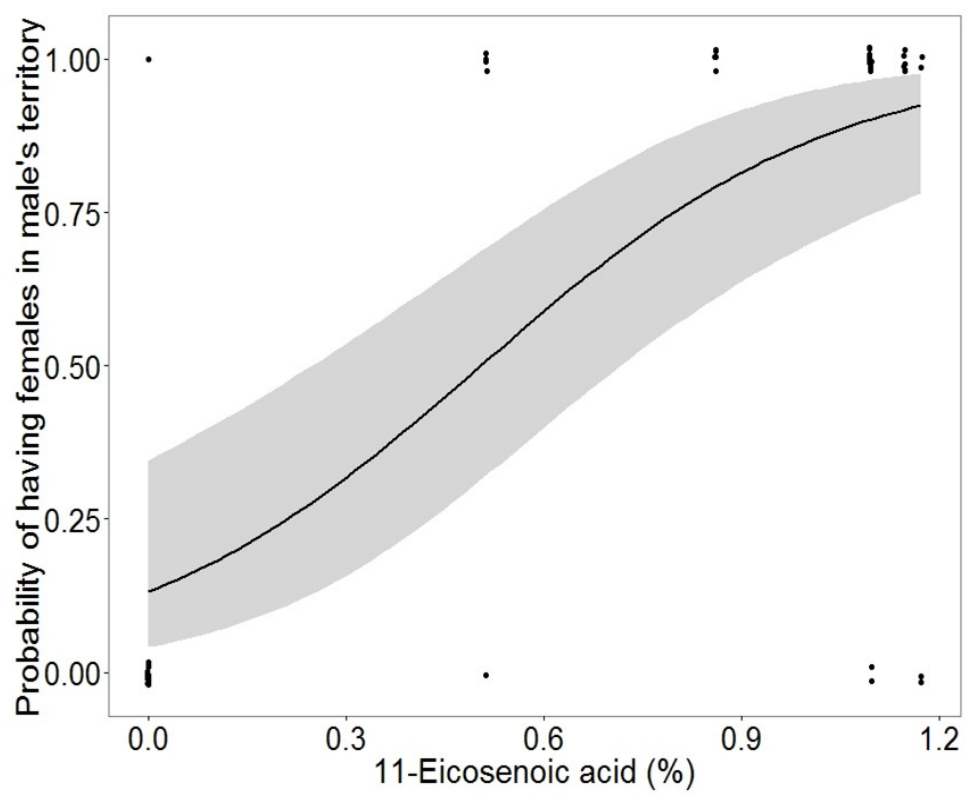

781

782 


\section{Fig. 6}

784

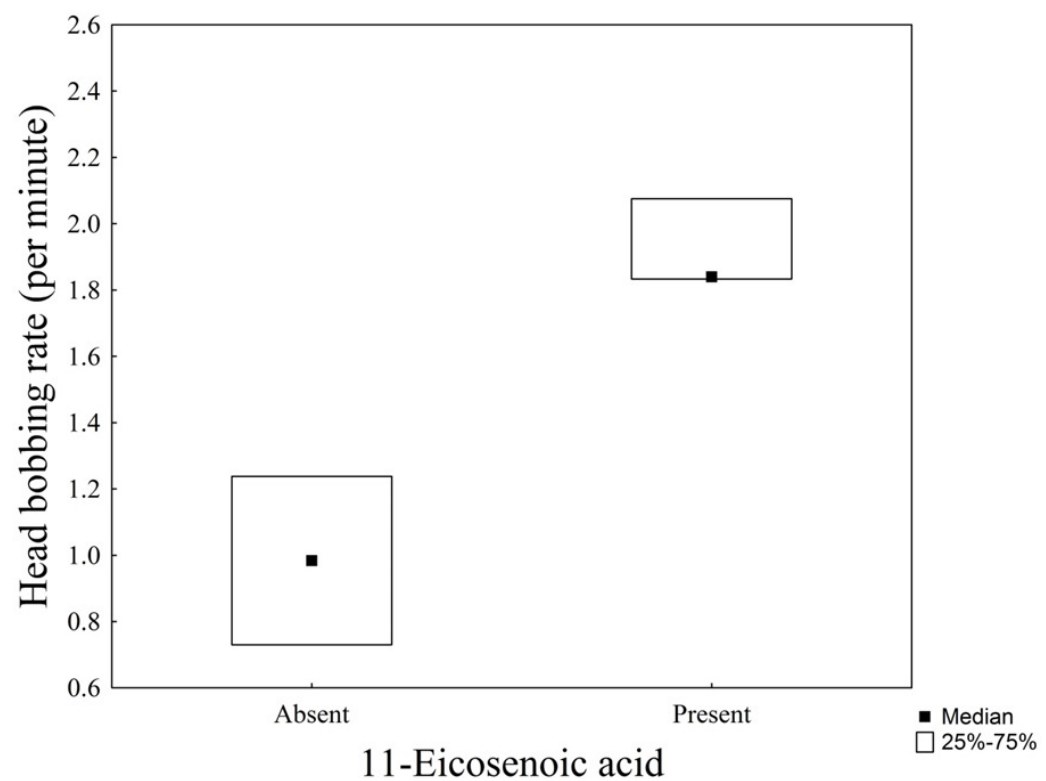

786

787 